\title{
VTE Risk Evaluation and Prophylaxis in Real Life Practice in Egyptian Hospitals
}

\author{
Sherif Sholkamy, MD \\ Department of Vascular Surgery, Ain Shams University Hospital, Egypt
}

Objective: This study was conducted to define global rate of patients at risk of venous thrombo-embolism (VTE) by type of acute illness (medical/surgical), to define factors driving prophylaxis decision in medical and surgical patients, to compare prescription modalities v/s international guidelines (ACCP) 2008, and to determine the proportion of at risk hospitalized patients who receive effective types of VTE prophylaxis.

Methods: This study was a cross sectional, observational study, conducted in medical and surgical wards. Recruitment was carried over nearly one year. Four hundred ninety five patients (495) were enrolled, 235 surgical patients aged 21 years or older undergoing an operation which requires general or epidural anaesthesia lasting at least $45 \mathrm{~min}$ and 260 medical patients aged 40 years or older admitted for treatment of acute medical illness. Patients were evaluated during a single visit.

Results: Out of 495 patients, 292 patients (59\%) were males and 203 patients (41\%) were females, the age range was between 21 and 93 years in the surgical group compared to between 40 and 90 years in the medical group, the mean ages were 59.28 \pm 12.51 in the medical group compared to $51.91 \pm 14.44$ in the surgical group, the percentage of patients at risk of VTE was (88.9\%) in the medical population and (3\%) in the surgical population, the most frequent risk factors in the medical population were acute infection $(30.8 \%)$, obesity $(30 \%)$, central venous catheter $(29.2 \%)$, chronic pulmonary disease $(21.9 \%)$, long term immobility $(21.9 \%)$, chronic heart failure $(21.2 \%)$ and acute respiratory failure $(19.6 \%)$.

The most frequent risk factors in surgical population were obesity $(38.3 \%)$, malignancy $(24.3 \%)$, central venous catheter $(20 \%)$, long term immobility $(16.2 \%)$, chronic heart failure $(16.2 \%)$, acute infection $(8.9 \%)$, chronic pulmonary disease $(8.9 \%)$ and cancer therapy $(4.3 \%)$.

The most common types of anticoagulant prophylaxis received by both medical and surgical population were low molecular weight heparin (91.4\%) and vitamin $\mathrm{K}$ antagonist (3.4\%).

Conclusion: VTE is a major public health issue. It is a preventable disease with a substantial risk of morbidity and mortality in patients hospitalised for acute medical and surgical conditions. Our data has shown that a large proportion of hospitalised individuals both surgical and medicalare at risk for VTE. Hospital-wide strategies to assess patients' VTE risk should be implemented, together with measures that ensure that at-risk patients receive appropriate VTE prophylaxis.

\begin{tabular}{llll}
\multicolumn{2}{l}{ Abbreviations } & & \\
\hline ACCP & American College of Chest Physician & $\mathrm{mn}$ & Minute \\
AE(s) & Adverse event(s) & $\mathrm{N}$ & Number of population \\
CRF(s) & Case report form(s) & $\mathrm{PE}$ & Pulmonary embolism \\
DVT & Deep venous thrombosis & QC & Quality control \\
ESH/ESC & European society of hypertension/ European society of cardiology & SAE(s) & Serious adverse event(s) \\
ESRD & End stage renal disease & SBP & Systolic blood pressure \\
GCP & Good clinical practice & SD & Standard deviation \\
GEP & Good epidemiology practice & SE & Standard error \\
GIT & Gastro-intestinal tract & UFH & Unfractionated heparin \\
GI & Gastro Intestinal & VKa & Vitamin K antagonist \\
GP & General practitioner & VTE & Venous thromboembolism \\
ICH & International conference & WHO & World health organization \\
LMWH & Low molecular weight heparin & &
\end{tabular}




\section{Introduction}

Venous thrombosis is the process of clot (thrombus) formation within veins, although this can occur in any venous system, the predominant clinical events occur in the vessels of the leg, giving rise to deep vein thrombosis, or in the lungs, resulting in a pulmonary embolism, collectively referred to as venous thromboembolism, the causes of VTE can be hereditary or acquired. A risk factor for thrombosis can be identified in over $80 \%$ of patients, but usually more than one factor is at play in a patient. ${ }^{1}$

The conditions commonly associated with hospitalization that increases risk of VTE are stroke, congestive heart failure, acute respiratory diseases, acute myocardial infarction, acute arthritis, acute infection, and inflammatory bowel disease, and the predisposing factors that increase risk of VTE are, recent or major surgery, immobility or paralysis, malignancy, previous VTE, older ages particularly over 80 years, estrogen therapy, obesity, central vein catheterization, varicose veins, and inherited or acquired thrombophilia. Patients hospitalized because of medical illness often have multiple risk factors for VTE, and these risks are generally cumulative. ${ }^{4,8}$ Accordingly, all patients should be evaluated for their risk of VTE at the time of hospital admission. This evaluation should be repeated whenever there is a significant change in a patient's clinical status. $^{8}$

The risk of VTE is increased ten fold in patients who are hospitalized after trauma, surgery or immobilizing medical illness, and also in pregnant and puerperal women. In many of these patients, DVT remains asymptomatic but in others it can cause morbidity and mortality. $11,13,16,17$ Screening studies for asymptomatic DVT have shown that DVT is common in such patients.

The goal of venous thromboembolism prophylaxis is to prevent VTE, thereby eliminating its complications, which include potentially fatal pulmonary embolism and postphlebitic syndrome, a long term disorder that reduces quality of life, is expensive for society and can lead to venous ulcers. ${ }^{28}$ This study provides an insight on VTE evaluation and prophylaxis is in real life practice in Egyptian hospitals by defining the rate of patients at risk of VTE by type of acute illness (medical/ surgical). Moreover, this study defines factors driving prophylaxis decision, compares prescription modalities versus international guidelines, and determins the proportions of at risk hospitalized patients who receive effective types of VTE prophylaxis.

\section{Patients and methods}

Study design: This was cross sectional, observational study that had been started on Jan 5, 2010, and completed on Dec 10, 2010. It was planned to enroll 500 patients. The patients were evaluated during a single visit.

The patients included in the study were, medical patients 40 years of age or older admitted for treatment of acute medical illness (IM \& ICU), or surgical patients 21 years of age or older undergoing an operation which requires general or epidural anaesthia lasting at least 45 min (general, ortho-surgery \& vascular surgery). The patients excluded were the pregnant or lactating women and the patients admitted for treatment of PE or DVT.

The study involved general, ortho and vascular surgeon wards. Each selected hospital ward should include at least 100 successive patients who meet the inclusion criteria at admission. This consecutive recruitment was to limit biases in patient selection, recruitment period was for 3 months. The treatment decision was left to the discretion of the physician and documented in the CRF (no therapeutic intervention).

The protocol was submitted to the Local Ethics Committee and the Ministry Of Health of Egypt for review and written approval. Both approvals were obtained before the initiation of the study.

The protocol complied with recommendations of the $18^{\text {th }}$ World Health Congress (Helsinki, 1964) and all applicable amendments, the protocol also complied with the laws and regulations of Egypt where the study was conducted.

Informed consent was obtained prior to the conduct of any study-related procedures. The patient informed consent form was constructed according to local regulations and requirements.

Study population: The criteria for evaluation were number of admitted patients to surgical and medical wards, to identify risk factors for VTE by type of illness, to describe the anticoagulation prescribed by type, dose, duration and time of initiation of VTE prophylaxis. Data for analysis was collected using a case report form.

Statical analysis: Statistical power and sample size justification: around 10,000 patients were admitted per quarter to surgical and medical wards in the selected hospitals which represent the public and private practice in different governorates all over Egypt. Our study was aiming to enroll 500 patients representing $5 \%$ of this targeted population in 3 months, descriptive 
analysis was performed for all variables in this study. Sample was described for demographic and background variables. Categorical variables were represented in frequency tables (number \& percent) while continuous variables such as age and weight were provided as (mean, standard deviation, standard error, mode, median, minimum and maximum). In addition, $x 2$ tests (chi-square test and its subsidiaries) were used to detect the significant change in categorical variables among study groups. Student's t-test was used to detect the significant change in continuous variables among study groups.

\section{Results}

In this study, 495 patients were consecutively recruited in 5 hospitals all over Egypt and two populations were defined, those admitted to hospital for medical reason [260 patients $(52.52 \%)$, the medical population] and those admitted to hospital for surgical reason [235 patients (47.48\%), the surgical population].

Demography: The study population consisted of $59 \%$ males and $41 \%$ females, the age range was between 21 and 93 years in the surgical group compared to $40: 90$ years in the medical group. The mean ages were $59.28 \pm 12.51$ in the medical group compared to $51.91 \pm 14.44$ in the surgical group, data quality control was performed on active sites.

Risk factors for VTE: Out of the 495 enrolled patients, 426 patients $(86.1 \%)$ were at risk of VTE representing 231 out of 260 (88.9\%) patients in the medical population and 195 out of 235 (83\%) patients in the surgical population.

Out of 231 (88.9\%) patients of medical population who were at risk of VTE, $71(27.3 \%)$ patients had one risk factor and $160(72.7 \%)$ patients had more than one risk factor of VTE, and out of 195 $(83 \%)$ patients of surgical population who were at risk of VTE, $101(42.9 \%)$ patients had one risk factor and 94 (57.1\%) patients had more than one risk factor of VTE.

The most frequent risk factors in medical population were acute infection, obesity, central venous catheter, chronic pulmonary disease, long term immobility, chronic heart failure and acute respiratory failure constituting 80 (30.8\%), 78 $(30 \%), 76(29.2 \%), 57(21.9 \%), 57$ (21.9\%), $55(21.2 \%)$ and $51(19.6 \%)$ respectively. On the other hand, the most frequent risk factors in surgical population were obesity, malignancy, central venous catheter, and long term immobility constituting $90(38.3 \%), 57(24.3 \%), 47(20 \%)$, $38(16.2 \%)$, respectively (Table 1 ).

Table 1

\begin{tabular}{|c|c|c|c|c|c|c|}
\hline \multirow{2}{*}{ Risk factors } & Surgical & n:235 & Medical & n:260 & Total & n:495 \\
\hline & Count & $\%$ & Count & $\%$ & Count & $\%$ \\
\hline Acute respiratory failure & 1 & $0.4 \%$ & 51 & $19.6 \%$ & 52 & $10.5 \%$ \\
\hline Acute inflammatory disorders & 6 & $2.6 \%$ & 13 & $5 \%$ & 19 & $3.8 \%$ \\
\hline Acute infection & 21 & $8.9 \%$ & 80 & $30.8 \%$ & 101 & $20.4 \%$ \\
\hline Active cancer & 57 & $24.3 \%$ & 15 & $5.8 \%$ & 72 & $14.5 \%$ \\
\hline Cancer therapy & 10 & $4.3 \%$ & 10 & $3.8 \%$ & 20 & $4.0 \%$ \\
\hline Recent ischemic stroke & 6 & $2.6 \%$ & 32 & $12.3 \%$ & 38 & $7.7 \%$ \\
\hline Chronic heart failure & 17 & $7.2 \%$ & 57 & $21.9 \%$ & 74 & $14.9 \%$ \\
\hline Previous venous thromboembolism & 21 & $8.9 \%$ & 55 & $21.2 \%$ & 76 & $15.4 \%$ \\
\hline Varicose veins & 2 & $0.9 \%$ & 5 & $1.9 \%$ & 7 & $1.4 \%$ \\
\hline Thrombophilia & 6 & $2.6 \%$ & 9 & $3.5 \%$ & 15 & $3.0 \%$ \\
\hline Previous superficial venous thrombosis & 1 & $0.4 \%$ & 2 & $0.8 \%$ & 3 & $0.6 \%$ \\
\hline Contraceptives / HRT & 1 & $0.4 \%$ & 1 & $0.4 \%$ & 2 & $0.4 \%$ \\
\hline Long term immobility & 38 & $16.2 \%$ & 57 & $21.9 \%$ & 95 & $19.2 \%$ \\
\hline Post-partum & 1 & $0.4 \%$ & 0 & $0 \%$ & 1 & $0.2 \%$ \\
\hline Obesity & 90 & $38.3 \%$ & 78 & $30 \%$ & 168 & $33.9 \%$ \\
\hline Central venous catheter & 47 & $20 \%$ & 76 & $29.2 \%$ & 123 & $24.8 \%$ \\
\hline
\end{tabular}

* Each patient may had more than one Risk factor

Factors Affecting thromboprophylaxis decision 
Out of 260 patients of the medical population, 10 (3.8\%) patients didn't receive thromboprophylaxis; 9 patients $(3.5 \%)$ were deemed to have risk factors for bleeding by the physicians: hepatic impairment $(1.5 \%)$, low platelet count (1.2\%) and esophageal varices $(1.2 \%)$.

On the other hand, out of 235 patients of the surgical population, $10(4.3 \%)$ patients didn't receive thromboprophylaxis; 7 patients $(3 \%)$ were deemed to have risk factors for bleeding such as concomitant administration of NSAID in $(1.7 \%)$ or low platelet count $(0.9 \%)$.

Prescription modalities vs international guidelines (ACCP): Out of the 260 patients comprising the Medical population, 453 patients $(91.5 \%)$ were administered LMWH \& 13 patients $(2.6 \%)$ were administered fondaparinux; following the ACCP guidelines which recommends thromboprophylaxis with LMWH or fondaparinux for medical patients admitted to the hospital who were confined to bed and had one or more additional risk factors. For the use of mechanical prophylaxis in the medical population, the most frequent type was graduated compression in $60(23.1 \%)$ patients, followed by intermittent pneumatic compression and foot pump in 12 $(4.6 \%)$ and $10(3.8 \%)$ patients respectively.

Out of the 235 patients comprising the surgical population, 215 patients $(91.5 \%)$ were administered LMWH and 6 patients (2.6\%) were administered fondaparinux. While 68 patients (28.9\%) were using a mechanical method for thromboprophylaxis; the most frequent type of mechanical prophylaxis in the surgical population was graduated compression constituting 63 $(26.8 \%)$ patients, followed by intermittent pneumatic compression constituting 5 (2.1\%) patients.

As per the ACCP guidelines for a patient who has had a symptomatic proximal DVT, it has been recommended the use of an elastic compression stocking with an ankle pressure gradient of 30 to $40 \mathrm{~mm} \mathrm{Hg}$ if feasible (Grade 1A). For patients with severe edema of the leg due to postthrombotic (phlebitic) syndrome, it has been suggested for a course of intermittent pneumatic compression (IPC) [Grade 2B].

VTE prophylaxis anticoagulant therapy prescription: Out of 495 patients, 475 (96\%) patients were receiving anticoagulant as a VTE prophylaxis. The most frequent types of anticoagulant prophylaxis received in medical population were low molecular weight heparin and vitamin $\mathrm{K}$ antagonists, followed by Fondaparinux and unfractionated heparin, while in the surgical population low molecular weight heparin, vitamin $\mathrm{K}$ antagonist and Fondaparinux were the most prescribed, followed by unfractionated heparin and other anticoagulants (Table 2).

Table 2

\begin{tabular}{|c|c|c|c|c|c|c|}
\hline \multicolumn{7}{|c|}{ Type of Anticoagulant prescribed } \\
\hline & \multicolumn{2}{|c|}{$\begin{array}{c}\text { Surgical } \\
\text { n: } 235\end{array}$} & \multicolumn{2}{|c|}{$\begin{array}{c}\text { Medical } \\
\mathrm{n}: 260\end{array}$} & \multicolumn{2}{|c|}{$\begin{array}{c}\text { Total } \\
\text { n:495 }\end{array}$} \\
\hline & Count & $\%$ & Count & $\%$ & Count & $\%$ \\
\hline Low Molecular Weight Heparin & 215 & $91.5 \%$ & 238 & $91.5 \%$ & 453 & $91.5 \%$ \\
\hline Unfractionated Heparin & 1 & $0.4 \%$ & 7 & $2.6 \%$ & 8 & $1.6 \%$ \\
\hline Vitamin K Antagonist & 8 & $3.4 \%$ & 9 & $3.5 \%$ & 17 & $3.4 \%$ \\
\hline Fondaparinux & 6 & $2.5 \%$ & 7 & $2.6 \%$ & 13 & $2.6 \%$ \\
\hline Other anticoagulants & 2 & $0.8 \%$ & 0 & $0 \%$ & 2 & $0.9 \%$ \\
\hline
\end{tabular}

The mean durations of anticoagulant prophylaxis received by the medical population were $6.94 \pm$ $4.16,6.57 \pm 4.791,5.22 \pm 5.53$ and $8.75 \pm 4.077$ days for low molecular weight heparin, unfractionated heparin, vitamin $\mathrm{K}$ antagonist and Fondaparinux respectively.

The mean durations of anticoagulant prophylaxis received by the surgical population were $6.30 \pm 3.913,11 \pm 0,6.25 \pm 3.77,8.50 \pm 3.83$ and $10 \pm 7.07$ days for low molecular weight heparin, unfractionated heparin, vitamin $\mathrm{K}$ antagonist, fondaparinux and other anticoagulant respectively.

The most frequent low molecular weight heparin received by the medical population was enoxaparin constituting $234(90 \%)$ followed by nadroparin constituting $1(0.4 \%)$ patient, while the most frequent low molecular weight heparin received by the surgical population was enoxaparin and tinzaparin constituting 212 (90.2\%) and 11 (4.7\%) respectively, followed by nadroparin constituting 2 $(0.9 \%)$ patients. 
Apart from anticoagulant treatments, the most frequent medications received by the medical population were clopidogrel/aspirin $65(25 \%)$, NSAIDS/ Cox II inhibitors 11 (4.2\%), dypiridamole $1(0.4 \%)$ and vitamin $\mathrm{K}$ antagonist by $1(0.4 \%)$ patient.

While in the surgical population, NSAIDS/ Cox II inhibitors, clopidogrel/aspirin, therapeutic LMWH, vitamin $\mathrm{K}$ antagonist and dypiridamole were given respectively in $65(25 \%), 11(4.2 \%), 1(0.4 \%)$, and $1(0.4 \%)$ patients.

\section{Discussion}

Venous thromboembolism (VTE) is an important cause of morbidity and mortality worldwide in a different varieties of patients and conditions. ${ }^{29}$ Once it has occurred, it will represent a huge burden both clinically and economically, the rate of patients at risk of VTE is increasing in hospitalized patients, in both surgical and medical patients, without thromboprophylaxis, the incidence of occurance of DVT ranges from $16 \%$ to $55 \%$ in medical and surgical patients and from $50 \%$ to $60 \%$ in patients who had a major orthopedic procedure. $^{29}$

Thus, Prophylaxis is the best solution to this problem, asit will decrease both clinical and economic cost tremendously. Administration of thromboprophylaxsis in both surgical patients and general medical patients proved beneficial in prevention of VTE. ${ }^{30,31}$

A study conducted by by Cohen AT et al, (ENDORSE study), only half of at-risk patients of VTE received an ACCP-recommended method of prophylaxis, Previous studies have reported overall VTE prophylaxis rates ranging from 13\% to $64 \%$. This variability is largely due to individual studies limiting their assessment to predefi ned populations (eg, orthopaedic surgery patients) and the substantial differences that can exist between institutions within a country, as shown by Otero and colleagues who reported prophylaxis rates of $27-70 \%$ across different hospitals in Spain.

Frequency of use of ACCP-recommended types of prophylaxis could be due to many factors, including physician awareness, availability of guidelines, education factors, reimbursement, and national health-care resources. ${ }^{32}$

In our study, the rate of patients at risk of developing VTE was 426 patients $(86.1 \%$ out of 495) representing 231 out of 260 (88.9\%) patients in the medical population and 195 out of 235 $(83 \%)$ patients in the surgical population.

ACCP guideline recommendations on the need for
VTE prophylaxis depends on the presence of risks for developing $\mathrm{VTE}^{33}$ the assessment of a patient's risk is based on a number of risk factors that was acknowledged from epidemiologic studies. The most commonly risk factors for VTE includes general surgeries, obesity, immobility, age, cancer therapy, malignancy, central vein catheterization, and acute infections. ${ }^{34}$

In our cross sectional study, the most commonly identified risk factors were; obesity (33.9\%) followed by central venous catheter $(24.8 \%)$, acute infection (20.4\%), long term immobility $(19.2 \%)$, Previous venous thromboembolism $(15.4 \%)$, chronic heart failure $(14.9 \%)$, active cancer $(14.5 \%)$, and acute respiratory failure $(10.5 \%)$.

Active cancer risk factor was significantly higher in surgical population than in medical population, while chronic heart failure, previous thromboembolism, central venous catheter, and long term immobility were higher in medical population.

Obesity was almost the same in the two population with the highest incidence rate $(33.9 \%)$. Factors that represented risk of bleeding in the studied population were concomitant use of NSAID (32.3\%) followed by significant renal impairment (9.5\%).

Regarding VTE prophylaxis therapy, clinical randomized trails defined the patients at risk of developing VTE and the efficacy of the appropriate pharmacologic measures in both medical and surgical populations. ${ }^{35-38}$

In our study, 475 out of 495 (96\%) patients received anticoagulant for VTE prophylaxis, the most commonly prescribed anticoagulant was Low Molecular Weight Heparin (453 patients=91.5\%) in both medical ( 238 patients $=91.5 \%$ ) and surgical population (215 patients $=91.5 \%)$, moreover, out of 495 patients, $119(24.04 \%)$ received mechanical prophylaxis, $75(28.8 \%)$ in the medical population and $44(18.7 \%)$ patients in the surgical population.

Twenty patients (4\%-ten patients in each group of population) did not receive prophylaxis therapy according to physician decision because of having one or more risk factors that may cause bleeding. These risk factors included; hepatic impairment, low platelet count, esophageal varices, known bleeding disorders, intracranial hemorrhage, NSAID, significant renal impairment, Active gastrointestinal bleed, and Bleeding at hospital admission.

This study has potential limitation that data might not represent other non participating hospitals in 
the country however the study includes 5 major hospitals in Egypt.

\section{Conclusion}

VTE is a major public health issue. ${ }^{38,39}$ It is a preventable disease that carries a substantial risk of morbidity and mortality in patients hospitalised for acute medical and surgical illnesses. Our data has shown that a large proportion of hospitalised individuals both surgical and medical are at risk for VTE. Hospital-wide strategies to assess patients' VTE risk should be implemented, together with measures that ensure that at-risk patients receive appropriate VTE prophylaxis. ${ }^{40,41}$

\section{Disclosure}

The study has been funded by Sanofi, and the auther has no conflict of interest.

\section{Reference}

1. Andrew D Blann, Gregory Y H: Lip Venous thromboembolism BMJ 2006; 332; 215-219 doi:10.1136/bmj.332.7535.215.

2. Weitz JI, Bates SM: New anticoagulants. $\boldsymbol{J}$ Thromb Haemostas 2005; 3: 1843-53.

3. Lapostolle F, Surget V, Borron SW, et al: Severe pulmonary embolism associated with air travel. N Engl J Med 2001; 345: 779-783.

4. Geerts $W H$, Bergqvist $D$, Pineo GF, Heit JA, Samama CM, Lassen MR, Colwell CW: Prevention of Venous Thromboembolism: American College of Chest Physicians (ACCP) Evidence-Based Clinical Practice Guidelines (8th Edition). Chest 2008: 381S-453S.

5. Goldhaber SZ, Tapson VF; DVT FREE Steering Committee: A prospective registry of 5,451 patients with ultrasound-confirmed deep vein thrombosis. Am J Cardiol 2004; 93: 259-262.

6. Lyman $\mathrm{GH}$, Khorana $\mathrm{AA}$, Falanga $\mathrm{A}$, et al; American Society of Clinical Oncology. American Society of Clinical Oncology guideline: Recommendations for venous thromboembolism prophylaxis and treatment in patients with cancer. J Clin Oncol 2007; 25: 5490-5505.

7. Goldhaber SZ. Pulmonary embolism. Lancet 2004; 363 :1295-1305.

8. Francis CW: Clinical practice. Prophylaxis for thromboembolism in hospitalized medical patients. N Engl J Med 2007; 356: 1438-1444.

9. White RH: The epidemiology of venous thromboembolism. Circulation 2003; 107: I4I8.
10. Heit JA, Silverstein MD, Mohr DN, Petterson TM, O'Fallon WM, Melton LJ $3^{\text {rd }}$ : Risk factors for deep vein thrombosis and pulmonary embolism: A population-based case-control study. Arch Intern Med 2000; 160: 809-815.

11. Bergqvist D: Postoperative thromboembolism: frequency, etiology, prophylaxis. Berlin: Springer-Verlag; 1983. [section 1.1] [section 1.2] [section 2] [section 3.1] [section 3.2.1] [section 4.1] [section 4.2.1] [section 6].

12. Scottish Intercollegiate Guidelines Network (SIGN). Antithrombotic therapy. Edinburgh: SIGN; 1999. (SIGN publication no. 36). [Cited 5 Sep 2002]. Available from url: http:// www.sign.ac.uk/guidelines/fulltext/36/index. $\mathrm{html}$ [section 1.1] [section 1.2] [section 1.3] [section 3.3.2] [section 3.3.3] [table 4] [section 3.4.4] [section 3.8] [section 6.3] [section 6.4.1] [section 7] [section 8.1.1] [section 8.1.2] [section 8.4] [section 13.3].

13. Sandler DA, Martin JF: Autopsy proven pulmonary embolism in hospital patients: are we detecting enough deep vein thrombosis? J R Soc Med 1989; 82: 203-5. [section 1.1] [section 1.2] [section 1.3] [section 8].

14. Gillies $T E$, Ruckley CV, Nixon SJ: Still missing the boat with fatal pulmonary embolism. $\boldsymbol{B r} \boldsymbol{J}$ Surg 1996; 83: 1394-5. [section 1.1] [section 1.3].

15. Franzeck UK, Schalch I, Jager KA, Schneider E, Grimm J, Bollinger A: Prospective 12-year follow-up study of clinical and hemodynamic sequelae after deep vein thrombosis in lowrisk patients (Zurich study). Circulation 1996; 93: 74-9. [section 1.1] [section 1.2].

16. Geerts WH, Heit JA, Clagett GP, Pineo GF, Colwell CW, Anderson FA Jr, et al: Prevention of venous thromboembolism. Chest 2001; 119 Suppl 1: 132-75. [section 1.2] [section 1.3] [section 1.6] [section 3.2.1] [section 3.2.3] [section 3.8] [section 3.9] [section 4.1] [section 4.3.2] [section 4.5] [section 5.1] [section 5.1.3] [section 5.1.4] [section 5.2.4] [section 5.4] [section 6.1.1] [section 6.2] [section 8].

17. Nicolaides AN, Arcelus J, Belcaro G, Bergqvist $D$, Borris LC, Buller HR, et al: Prevention of venous thromboembolism. European Consensus Statement, 1-5 November 1991, developed at Oakley Court Hotel, Windsor, UK. Int Angiol 1992; 11: 151-9. [section 1] [section 3.2.1] [section 3.2.3] [section 3.8] [section 4] [section 5] [section 6.1.1] [section 6.2] [section 6.4.1]. 
18. Risk of and prophylaxis for venous thromboembolism in hospital patients. Thromboembolic Risk Factors (THRIFT) Consensus Group. BMJ 1992; 305: 567-74.

19. Scottish Intercollegiate Guidelines Network (SIGN): Prophylaxis of venous thromboembolism. Edinburgh: SIGN; 1995. (SIGN publication no.1). [section 1.2] [section 1.3] [section 1.4] [section 5].

20. Donaldson GA, Williams C, Scannell JG, Shaw RS: A reappraisal of the application of the Trendelenburg operation to massive fatal embolism. N Engl J Med 1963; 268: 171-4.

21. Dalen JE, Alpert JS: Natural history of pulmonary embolism. Prog Cardiovasc Dis 1975; 17: 259-70.

22. Perez JV, Warwick DJ, Case CP, Bannister GC: Death after proximal femoral fracturean autopsy study. Injury 1995; 26: 237-40. [section 1] [section 5].

23. Good epidemiology practice (GEP) proper conduct in epidemiologic research. Prepared for the IEA European Federation. Adopted by the IEA and "societies" in 2004. Updated in June 2004. IEA European Federation.

24. Ansell $\mathrm{J}^{1}$, Bergqvist $\mathrm{D}^{2}$ : Current Options in the Prevention of Thromboembolic Disease. Updated in 2004. 1Boston University Medical Center, Boston, USA2 Department of Surgical Sciences, University Hospital, Uppsala, Sweden.

25. Silverstein MD, Heit JA, Mohr DN, Petterson TM, O'Fallon WM, Melton LJ 3d: Trends in the incidence of deep vein thrombosis and pulmonary embolism: a 25-year populationbased study. Arch Intern Med 1998; 158: 58593.

26. Moser KM, LeMoine JR. Is embolic risk conditioned by location of deep venous thrombosis? Ann Intern Med 1981; 94: 43944.

27. Paget J: Clinical lectures and essays. London: Longmans, Green 1875.

28. Bergqvist $D$, Jendteg $S$, Johansen $L$, et al: Cost of long-term complications of deep venous thrombosis of the lower extremities: an analysis of a defined patient population in Sweden. Arch Intern Med 1997; 126: 454-7.

29. Geerts WH, Heit JA, Clagett GP, et al: Prevention of venous thromboembolism. Chest 2001; 119: 132S-175S.
30. Goldhaber SZ: Venous thromboembolism prophylaxis in medical patients. Thromb Haemost 1999; 828: 99-901.

31. Sandler DA, Martin JF: Autopsy proven pulmonary embolism in hospital patients: are we detecting enough deep vein thrombosis? $\boldsymbol{J}$ R Soc Med 1989; 82: 203-205.

32. Cohen AT, et al: Venous thromboembolism risk and prophylaxis in the acute hospital care setting (ENDORSE study): a multinational cross-sectional study. Lancet 2008; 371: 38794.

33. Kearon $C^{1}$, Kahn SR, Agnelli $G$, et al: Antithrombotic therapy for venous thromboembolic disease: American College of Chest Physicians Evidence-Based Clinical Practice Guidelines (8th Edition). Chest 2008; 133: 454S-545S.

34. Joseph A: Caprini, MD, MS, FACS, RVT, FACPh. Update on Risk Factors for Venous Thromboembolism. The American Journal of Medicine. http://www.venousdisease.com/ Publications/Update\%20on \%20risk\%20 factors-caprini.pdf.

35. Samama MM, Cohen AT, Darmon JY, et al: A comparison of enoxaparin with placebo for the prevention of venous thromboembolism in acutely ill medical patients: Prophylaxis in Medical Patients With Enoxaparin Study Group. N Engl J Med. 1999; 341: 793- 800.

36. Kleber FX, Witt C, Vogel G, Koppenhagen K, Flosbach CW for THE-PRINCE Study Group: Randomized comparison of enoxaparin with unfractionated heparin for the prevention of venous thromboembolism in medical patients with heart failure or severe respiratory disease. Am Heart J 2003; 145: 614-621.

37. Nicolaides AN, Breddin HK, Fareed J, et al: Prevention of venous thromboembolism: International Consensus Statement: guidelines compiled in accordance with the scientific evidence. Int Angiol. 2001;201- 3738. Nieto JA, Cámara T, Camacho I; MEDITROM Investigators. Venous thromboembolism prophylaxis in acutely ill hospitalized medical patients. A retrospective multicenter study. Eur J Intern Med 2014; 25: 717-723. doi: 10.1016/j.ejim.2014.07.005.

38. Anderson FA Jr, Zayaruzny M, Heit JA, Fidan $D$, Cohen AT: Estimated annual numbers of US acute-care hospital patients at risk for venous thromboembolism. Am J Hematol 2007; 82: 777-782. 
39. Cohen AT, Agnelli G, Anderson FA Jr, et al: Venous thromboembolism in Europe: the number of VTE events and associated morbidity and mortality. Thromb Haemost 2007; 98: 756-764.

40. Geerts WH, Pineo GF, Heit JA, et al: Prevention of venous thromboembolism: the Seventh ACCP Conference on Antithrombotic and
Thrombolytic Therapy. Chest 2004; 126: 338S-400S.

41. Kakkar W, Corrigan TP, Fossard DP, Sutherland I, Shelton MG, Thirlwall J: Prevention of fatal postoperative pulmonary embolism by low doses of heparin: an international multicentre trial. Lancet 1975; 306: 45-51. 